\title{
Asset Price Momentum and Monetary Policy: Time-varying Parameter Estimation of Taylor Rules
}

Anastasios G. Malliaris

Loyola University Chicago, tmallia@luc.edu

Ramaprasad Bhar

The University of New South Wales

Follow this and additional works at: https://ecommons.luc.edu/business_facpubs

Part of the Business Commons

\section{Author Manuscript}

This is a pre-publication author manuscript of the final, published article.

\section{Recommended Citation}

Malliaris, Anastasios G. and Bhar, Ramaprasad. Asset Price Momentum and Monetary Policy: Timevarying Parameter Estimation of Taylor Rules. Applied Economics, 48, 55: 5329-5339, 2016. Retrieved from Loyola eCommons, School of Business: Faculty Publications and Other Works, http://dx.doi.org/ 10.1080/00036846.2016.1176117

This Article is brought to you for free and open access by the Faculty Publications and Other Works by Department at Loyola eCommons. It has been accepted for inclusion in School of Business: Faculty Publications and Other Works by an authorized administrator of Loyola eCommons. For more information, please contact ecommons@luc.edu. c) $($ () $\ominus$

This work is licensed under a Creative Commons Attribution-Noncommercial-No Derivative Works 3.0 License. (C) Taylor \& Francis 2014 


\title{
ASSET PRICE MOMENTUM AND MONETARY POLICY: TIME VARYING PARAMETER ESTIMATION OF TAYLOR RULES
}

\author{
Ramaprasad Bhar \\ School of Risk and Actuarial Studies \\ The University of New South Wales \\ E-mail: R.Bhar@unsw.edu.au \\ and \\ A. G. Malliaris \\ Department of Economics and Finance \\ Quinlan School of Business \\ Loyola University Chicago \\ E-mail: tmallia@luc.edu
}

\begin{abstract}
.
In this paper we consider two new independent variables as inputs to the Taylor Rule. These are the equity and housing momentum variables and are introduced to investigate the potential usefulness of these two variables in guiding the Fed to lean against potential bubbles. Such effectiveness cannot adequately be evaluated if the Taylor Rule estimation follows the standard regression methodology that has been criticized in the literature to be econometrically incorrect. Using a time varying parameter estimation methodology we find that equity momentum as an input in the Taylor Rule does not contribute to changes in Fed Funds. However, the housing momentum plays an important role econometrically and can be a useful tool in setting Fed Funds rates.
\end{abstract}

Key Words: Monetary policy rule, Nonlinear model, Stock market, Housing market, Timevarying coefficient

JEL Classification: C22, E44, G12

Current Revised Version: September 17, 2013. 


\section{ASSET PRICE MOMENTUM AND MONETARY POLICY: TIME VARYING PARAMETER ESTIMATION OF TAYLOR RULES}

\section{INTRODUCTION}

The global financial crisis of 2007-09 started early in 2007 as a subprime loan crisis and evolved into a major financial crisis that affected, seriously, the U.S. and global economies. In the U.S., the great recession associated with this financial crisis lasted 18 months between December 2007 and June 2009. Federal Reserve Chairman Ben Bernanke (2013) describes this crisis in detail calling it the worst financial crisis in modern history.

The likely causes of this severe global financial crisis are manifold and embrace the following three broad categories: First, microeconomic factors played an important role. These include subprime lending, financial innovation and opaque derivative securities, excessive risk taking, inadequate risk management strategies, financial deregulation, problems with rating agencies and originate to distribute models, ethical (greed and corruption) and even psychological (animal spirits). The second group involves macroeconomic factors such as the decline in real estate prices and monetary policy (low interest rates during 2002-4, ambiguity about the role of central banks to address asset price bubbles). Finally, global factors, such as the international saving glut, fixed exchange rates for certain countries such as China, and free global capital mobility.

The intensity, complexity, and length of the crisis justify the multiplicity of causal factors. In this essay we refocus the analysis on the second group of factors and argue that their investigation can give us valuable clues, both about the occurrence of the crisis and how to prevent future ones.

\section{PURPOSE OF THIS PAPER}

It is the purpose of this paper to investigate the role of monetary policy in the U.S. as the starting point of the global financial crisis. Most economists agree that the bursting of the housing bubble is the basic macroeconomic cause of the financial crisis. As the graph below indicates, the price of the average house in the U.S. increased dramatically beginning around 2002 and after 
reaching a peak in early 2007, it started correcting with an eventual drop of about $35 \%$. The increases and declines were significantly higher in certain areas like Florida, California, and Nevada, and much lower in others.

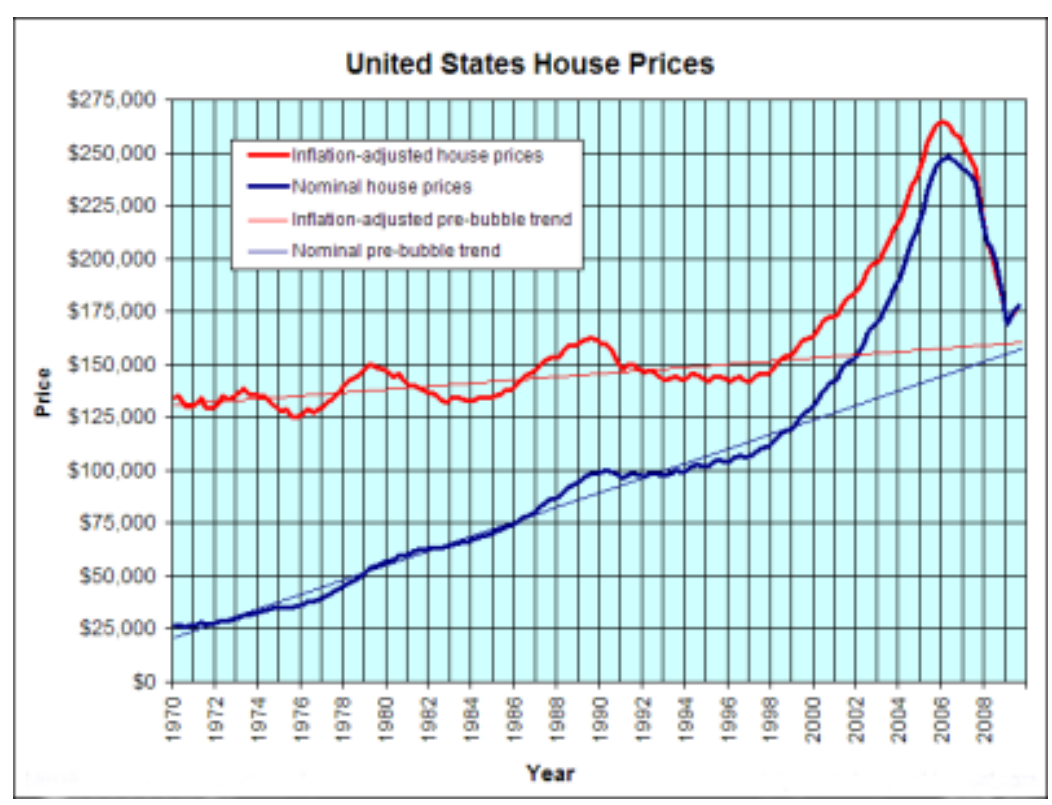

This real estate bubble can in turn be traced to an easy monetary policy during the 20022005 period. The story told by several authors such as Taylor (2007) is that the bursting of the internet bubble in 2001 destabilized financial markets and wiped out about 30\% of the stock market capitalization causing substantial losses in household wealth. The Fed initiated significant decreases in Fed Funds rates and kept them low for too long. The famous graph Taylor presents to substantiate his argument is presented below. 


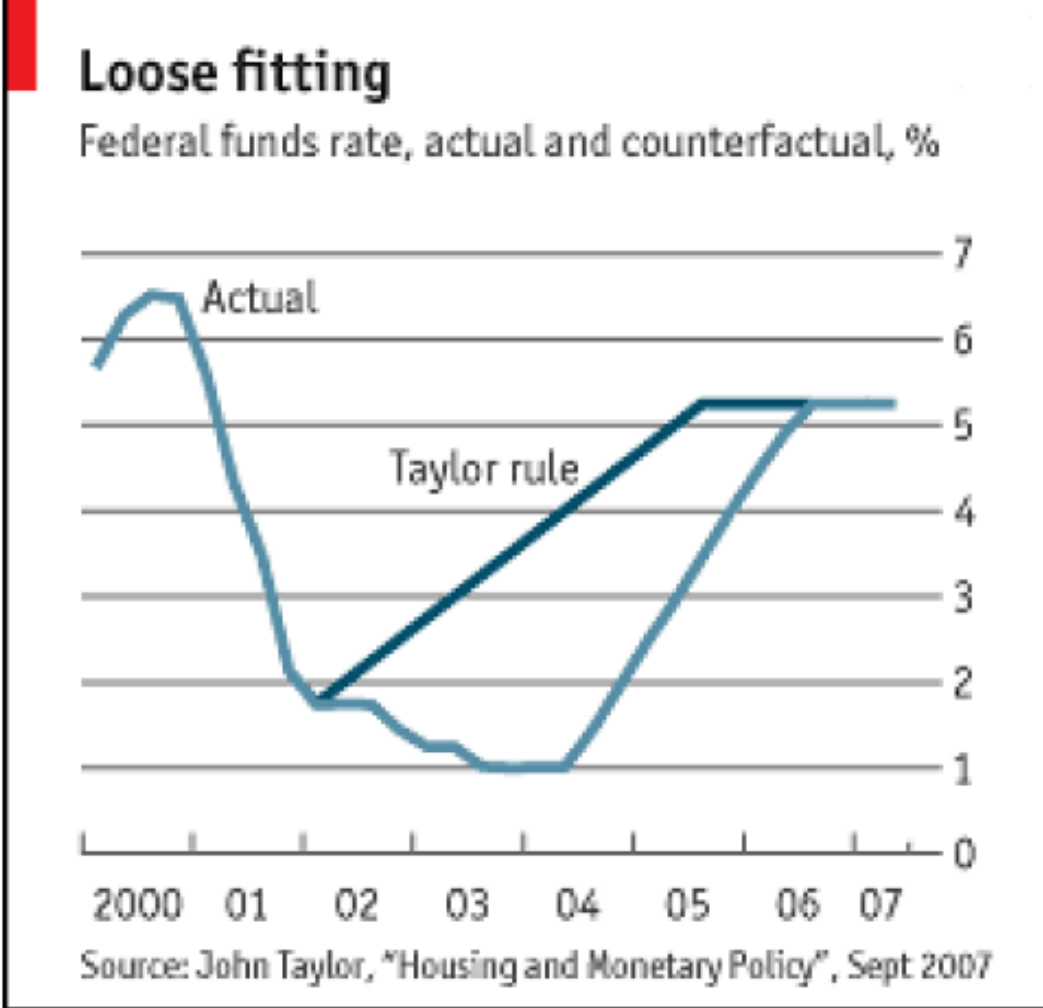

The easy monetary policy by the Fed during 2000-2004 to offset the bursting of the internet bubble contributed to a dramatic increase in the demand for housing. In turn, this increased demand for housing caused prices to increase significantly during 2002-2006 in the U.S. Similar policies in several other countries such as the U.K., Ireland, and Spain, fueled a global real estate boom. As a consequence of the falling housing prices beginning in early 2007 , the prices of securitized mortgages fell and in particular subprime mortgages fell quite dramatically, affecting financial markets worldwide.

This story however is not acceptable to all. Bernanke (2010) gives detailed evidence that Federal Reserve Fed Funds policies are not responsible for the housing bubble; the central argument is the global character of the housing bubble. Put differently, if housing prices increased across many different countries following dissimilar monetary policies, Taylor's graph above fails to explain the determinant of the bubble. In this debate, Bernanke proposes the hypothesis that it was the global saving glut as the more likely factor that powered to the global housing boom. 
To contribute to a better understanding of the role of monetary policy with respect to asset bubbles we focus on the Taylor Rule as a tool of monetary policy in the U.S. In the next section we discuss both the essence of the Taylor Rule as well as its theoretical and econometric shortcomings. Then we estimate the Taylor Rule doing the econometrics correctly but also extending the Taylor Rule to incorporate new variables that capture the momentum behavior of asset bubbles, both equity and housing.

\section{REVIEW OF THE LITERATURE}

In an influential paper, Taylor (1993) proposed a simple policy rule for computing the nominal Fed Funds rate. Taylor argued that the nominal Fed Funds rate is the sum of four terms: the real interest rate, the inflation rate; the weighted deviation of inflation from the inflation target and the weighted output gap. Kohn (2007) evaluates this contribution of John Taylor and concludes that "his framework has been enormously important to policymaking in the Federal Reserve, and it has yielded many benefits. Nevertheless, it is important to keep in mind that some significant practical limitations also are associated with the application of such rules in real time. In other words, "it is not so simple to use simple rules" (p.3). Cochrane (2011) gives a comprehensive evaluation of the theoretical foundations of the Taylor Rule and argues that such a rule is not identified without unrealistic assumptions.

This paper recognizes the initial simplicity of the Taylor Rule, particularly during periods of financial instabilities that arise from the bursting of asset bubbles. There is an enormous literature on financial bubbles presented in Evanoff, Kaufman and Malliaris (2012). In this paper we augment the Taylor Rule by considering an equity bubble and a housing bubble. Because the financial system is procyclical and the policy setting doesn't take financial imbalances into consideration, the low interest rate leads to over-optimistic attitude towards the future. As a consequence, investors are encouraged to purchase assets using borrowed money, and asset prices for either equity or housing increase faster than if interest rates were higher. The housing market is a good example for boom-and-bust cycle. Easy monetary policy makes financing cheaper.

In addition to considering additional factors in the determination of Fed Funds, we also take into consideration the various econometric critiques of the simple Taylor Rule. Österholm 
(2005) suggests that Taylor (1993) is a simple but an important contribution to the discipline of monetary economics. Although it has inspired much empirical studies, the econometric analysis has not been satisfactory. Taylor Rule may be somewhat less appropriate characterisation of the central banks' behaviour. Österholm finds near integrated behaviour of the included variables but there is very little support of cointegration in much of the sample period analysed. Although some studies include serially correlated error terms the possibility of misspecification remains.

Österholm (2005) goes on to confirm that it is hard to find support for the Taylor Rule in the inflation targeting small open economies. The author also suggests that augmenting the Taylor Rule with other variables may achieve a specification that better fits the 'true' monetary policy reaction function of the central banks. It may also be necessary to experiment with a forward-looking version of the Taylor Rule and possibly using real time data. Finally, Österholm makes the point that great care is needed in estimation of Taylor Rule models and statements are made about central bank policy because it is likely that parameters are inconsistently estimated.

In a related article Kim, Kishor and Nelson (2006) time varying nature of the monetary policy conducted by the central bank and find improvement in the overall performance of the model by including measurement error in the process. They report a significant change in the response of the Federal Funds rate to changes in the determining variables used in the model e.g. expected output gap and inflation.

In a similar vein Mandler (2008) presents a simple model of monetary policy in the U.S. that separates the forecast uncertainty about future values of the Federal Funds Rate into uncertainty about the state of the economy in the future and uncertainty about how the central bank will react to it. Mandler combines a Taylor Rule with a model of economic fundamentals to disentangle economically interpretable components of forecast uncertainty i.e. uncertainty about future economic conditions and uncertainty about future monetary policy.

The central unifying theme about the approaches by Kim, Kishor and Nelson (2006) and Mandler (2008) is that the models belong to the unobserved component type and requires Kalman filter for estimation. In this paper we also adopt this style and employ an expanded version of the Taylor type model to uncover the effect of equity market and real estate market on the determination of the Federal Funds rate.

The initial question of how the central bank should respond to an asset bubble can be reformulated in two ways. First, how does the central bank respond to an asset bubble while it is 
growing, and second, how does it respond after the bubble bursts? There has been strong agreement among economists that a central bank should respond to the bursting of a bubble by aggressively decreasing the Fed Funds rate to minimize the impact of financial instability on the real economy. Achieving maximum employment is one of the Fed's mandates. However, there is no clear answer to the question of how should the central bank respond to an asset bubble before

it bursts. If there is evidence that the bubble is contributing to inflation, then the Fed will respond; but what if prices remain stable? Some economists argue that the central bank should not respond to the bubble prior to its bursting while others believe that it should try to target it or at least lean against the bubble to avoid future financial instability.

Thus, we have two broad responses: the asymmetric approach, mentioned earlier, that advocates no response prior to the bursting and the symmetric approach that argues that the central bank should respond to an asset bubble both before and after it bursts. Within the choice of the symmetric response there are various degrees of intensity: burst the bubble, target the bubble or lean against it. Targeting the bubble during its growth elevates the importance of bubbles to the goal of inflation targeting. Leaning against an asset bubble is a weaker strategy. Kohn $(2006,2008)$ uses the terminology of "conventional strategy", focusing on the Fed's mandate to describe the asymmetric approach, versus "extra action" for the symmetric response when the Fed takes steps against an asset bubble. These questions were debated for several years before the 2002 "Jackson Hole Consensus", supporting the asymmetric approach to asset bubbles, was reached.

The 2007-09 global financial crisis undermined the Jackson Hole Consensus and the new central bank policy paradigm has shifted towards "leaning against bubbles." This means that an examination of issues involving asset bubbles, financial instabilities and monetary policies is necessary. Another way to state the intention of this paper is to say that financial instabilities created by the bursting of asset bubbles can be extremely disruptive to the real economy, and that the policy of "leaning against" potential bubbles need further examination.

\section{HYPOTHESES}

We are setting up the model for the Federal Funds rate $\mathrm{FF}_{\mathrm{t}}$ in the spirit of Taylor Rule on an ex post basis, but modulated by the feedback from asset markets as well as any impact from 
behavioural variables. The asset market feedback is investigated from both the equity market S\&P 500 as well as from the housing market Shiller Index. The behavioural components are captured by the momentum returns from both the equity market as well as the housing index return. The definition of the momentum returns is already given in the earlier document.

In addition to the above we define a proxy for the behavioral variable to represent recent performance or momentum return. We follow the definition used in Koijen, Rodriguez and Sbuelz (2009). In their continuous time set up for strategic an asset allocation problem, they allow the short-term performance of the equity market as a weighted function of the past returns. Given that $S_{t}$ represents the index level at time $t$, then the momentum return, $\mathrm{mmt}_{\mathrm{t}}$ is given by:

$$
\mathrm{mmt}_{\mathrm{t}}=\int_{0}^{\mathrm{t}} \mathrm{e}^{-(\mathrm{t}-\mathrm{u})} \frac{\mathrm{dS_{ \textrm {u } }}}{\mathrm{S}_{\mathrm{u}}}
$$

where $\mathrm{e}^{-(\mathrm{t}-\mathrm{u})}$ is the weighting scheme. Koijen et al (2009) show that there is no need to consider any more general weighting scheme since this simple approach is capable of matching the shortterm and long-term autocorrelations of the stock return or housing. The discrete version of this new explanatory performance variable $\mathrm{mmt}_{\mathrm{t}}$ captures the momentum return defined as,

$$
\mathrm{mmt}_{\mathrm{t}} \approx \sum_{\mathrm{i}=1}^{\mathrm{t}} \mathrm{e}^{-\mathrm{i}} \mathrm{r}_{\mathrm{t}-\mathrm{i}+1},
$$

where $r_{t}$ is $S \& P 500$ price level based return for the month $t$. In a similar manner the performance variable for the housing market is defined as,

$$
\mathrm{m}_{-} \mathrm{H}_{\mathrm{t}} \approx \sum_{\mathrm{i}=1}^{\mathrm{t}} \mathrm{e}^{-\mathrm{i}} \mathrm{H}_{\mathrm{t}-\mathrm{i}+1},
$$

where $H_{t}$ is the housing index level based return for the month $t$.

With this background, we wish to formulate our hypotheses as follows: extending the Taylor Rule(s) to include proxies for asset bubbles either in equity markets or housing and also improving the econometrics of estimating such extended Taylor Rules can offer better guidance to the Federal Reserve and improve its monetary policies.

The time varying parameter (TVP) set up for the Federal Funds rate $\mathrm{FF}_{\mathrm{t}}$ with interaction from the equity market and the housing market may be described by the following set of equations: 
Measurement equation:

$$
\begin{aligned}
\mathrm{FF}_{\mathrm{t}} & =\alpha_{0}+\alpha_{1, \mathrm{t}}\left(\pi_{\mathrm{t}}-0.02\right)+\alpha_{2, \mathrm{t}}\left(\mathrm{u}_{\mathrm{t}}-0.04\right)+\alpha_{3, \mathrm{t}}\left(\mathrm{R}_{\mathrm{t}-1}-0.08\right)+\alpha_{4, \mathrm{t}}\left(\mathrm{H}_{\mathrm{t}-1}-0.0383\right)+\varepsilon_{\mathrm{t}} \\
\varepsilon_{\mathrm{t}} & \sim \mathrm{N}\left(0, \sigma_{\varepsilon}^{2}\right)
\end{aligned}
$$

State transition equation:

$$
\left[\begin{array}{l}
\alpha_{1, \mathrm{t}} \\
\alpha_{2, \mathrm{t}} \\
\alpha_{3, \mathrm{t}} \\
\alpha_{4, \mathrm{t}}
\end{array}\right]=\left[\begin{array}{llll}
1 & 0 & 0 & 0 \\
0 & 1 & 0 & 0 \\
0 & 0 & 1 & 0 \\
0 & 0 & 0 & 1
\end{array}\right]\left[\begin{array}{l}
\alpha_{1, \mathrm{t}-1} \\
\alpha_{2, \mathrm{t}-1} \\
\alpha_{3, \mathrm{t}-1} \\
\alpha_{4, \mathrm{t}-1}
\end{array}\right]+\left[\begin{array}{c}
\eta_{1, \mathrm{t}} \\
\eta_{2, \mathrm{t}} \\
\eta_{3, \mathrm{t}} \\
\eta_{4, \mathrm{t}}
\end{array}\right],\left[\begin{array}{l}
\eta_{1, \mathrm{t}} \\
\eta_{2, \mathrm{t}} \\
\eta_{3, \mathrm{t}} \\
\eta_{4, \mathrm{t}}
\end{array}\right] \square \mathrm{N}\left(\left[\begin{array}{l}
0 \\
0 \\
0 \\
0
\end{array}\right],\left[\begin{array}{cccc}
\sigma_{\eta 1}^{2} & 0 & 0 & 0 \\
0 & \sigma_{\eta 2}^{2} & 0 & 0 \\
0 & 0 & \sigma_{\eta 3}^{2} & 0 \\
0 & 0 & 0 & \sigma_{\eta 4}^{2}
\end{array}\right]\right)
$$

The error terms in the measurement equation and the state equations are uncorrelated. The parameters of the models embedded in these equations and the filtered and the smoothed estimates of the time varying parameters are to be estimated from the observed variables. The details of the estimation procedure are described below.

\section{ESTIMATION OF THE PARAMETERS OF THE TVP MODEL}

We describe briefly how the unknown parameters in the TVP model may be estimated. Our aim is to present an overview of the filtering and smoothing algorithm (known as Kalman filter and smoother) and the optimization of the likelihood function. Before proceeding, however, it is advantageous to express the TVP model in term of suitable notations. This is advantageous since the discussion here is applicable to any such state space formulation and not restricted to only TVP models.

We consider the following generic representation of the TVP setup and the estimation process is considered in that context:

$$
\mathrm{y}_{\mathrm{t}}=\Gamma \mathrm{y}_{\mathrm{t}-1}+\mathrm{w}_{\mathrm{t}},(\text { State equation })
$$




$$
\mathrm{z}_{\mathrm{t}}=\mathrm{A}_{\mathrm{t}} \mathrm{y}_{\mathrm{t}}+\mathrm{v}_{\mathrm{t}} \text {, (Measurement equation). }
$$

In this TVP model, $y_{t}$ is a $p \times 1$ vector of unobserved state variables, $\Gamma$ is the $p \times p$ state transition matrix governing the evolution of the state vector. $\mathrm{w}_{\mathrm{t}}$ is the $\mathrm{p} \times 1$ vector of independently and identically distributed, zero-mean normal vector with covariance matrix Q. The state process is assumed to have started with the initial value given by the vector, $\mathrm{y}_{0}$, taken from normally distributed variables with mean vector $\mu_{0}$ and the $\mathrm{p} \times \mathrm{p}$ covariance matrix, $\Sigma_{0}$.

The state vector itself is not observed but some transformation of these is observed but in a linearly added noisy environment. In this sense, the $q \times 1$ vector $z_{t}$ is observed through the $q \times p$ measurement matrix $A_{t}$ together with the $q \times 1$ Gaussian white noise $v_{t}$, with the covariance matrix, $\mathrm{R}$. We also assume that the two noise sources in the state and the measurement equations are uncorrelated.

The next step is to make use of the Gaussian assumptions and produce estimates of the underlying unobserved state vector given the measurements up to a particular point in time. In other words, we would like to find out, $\mathrm{E}\left(\mathrm{y}_{\mathrm{t}} \mid\left\{\mathrm{z}_{\mathrm{t}-1}, \mathrm{z}_{\mathrm{t}-2} \cdots \mathrm{z}_{1}\right\}\right)$ and the covariance matrix, $\mathrm{P}_{\mathrm{t} \mid \mathrm{t}-1}=\mathrm{E}\left[\left(\mathrm{y}_{\mathrm{t}}-\mathrm{y}_{\mathrm{t} \mid \mathrm{t}-1}\right)\left(\mathrm{y}_{\mathrm{t}}-\mathrm{y}_{\mathrm{t} \mid \mathrm{t}-1}\right)^{\prime}\right]$. This is achieved by using Kalman filter and the basic system of equations is described below.

Given the initial conditions $\mathrm{y}_{0 \mid 0}=\mu_{0}$, and $\mathrm{P}_{0 \mid 0}=\Sigma_{0}$, for observations made at time $1,2,3 \ldots \mathrm{T}$,

$$
\begin{aligned}
& \mathrm{y}_{\mathrm{t} t \mathrm{t}-1}=\Gamma \mathrm{y}_{\mathrm{t}-1 \mid \mathrm{t}-1}, \\
& \mathrm{P}_{\mathrm{t} \mid \mathrm{t}-1}=\Gamma \mathrm{P}_{\mathrm{t}-1 \mid t-1} \Gamma^{\prime}+\mathrm{Q}, \\
& \mathrm{y}_{\mathrm{t} \mid \mathrm{t}}=\mathrm{y}_{\mathrm{t} \mid \mathrm{t}-1}+\mathrm{K}_{\mathrm{t}}\left(\mathrm{z}_{\mathrm{t}}-\mathrm{A}_{\mathrm{t}} \mathrm{z}_{\mathrm{t} \mid \mathrm{t}-1}\right) \text {, where the Kalman gain matrix } \\
& \mathrm{K}_{\mathrm{t}}=\mathrm{P}_{\mathrm{t} \mid \mathrm{t}-1} \mathrm{~A}_{\mathrm{t}}^{\prime}\left[\mathrm{A}_{\mathrm{t}} \mathrm{P}_{\mathrm{t} \mid \mathrm{t}-1} \mathrm{~A}^{\prime}+\mathrm{R}\right]^{-1},
\end{aligned}
$$

and the covariance matrix $\mathrm{P}_{\mathrm{t} \mid \mathrm{t}}$ after the $\mathrm{t}^{\text {th }}$ measurement has been made is, 


$$
P_{t \mid t}=\left[I-K_{t} A_{t}\right] P_{t \mid t-1} .
$$

Equation (5.3) forecasts the state vector for the next period given the current state vector. Using this one step ahead forecast of the state vector it is possible to define the innovation vector as,

$$
v_{t}=z_{t}-A_{t} y_{t \mid t-1}
$$

and its covariance as,

$$
\Sigma_{\mathrm{t}}=\mathrm{A}_{\mathrm{t}} \mathrm{P}_{\mathrm{t} \mid \mathrm{t}-1} \mathrm{~A}_{\mathrm{t}}^{\prime}+\mathrm{R} .
$$

Since in finance and economic applications all the observations are available, it is possible to improve the estimates of state vector based upon the whole sample. This is referred to as Kalman smoother and it starts with initial conditions at the last measurement point ie $\mathrm{y}_{\mathrm{T} \mid \mathrm{T}}$ and $\mathrm{P}_{\mathrm{T} \mid \mathrm{T}}$. The following set of equations describes the smoother algorithm:

$$
\begin{aligned}
& \mathrm{y}_{\mathrm{t}-1 \mid \mathrm{T}}=\mathrm{y}_{\mathrm{t}-1 \mid \mathrm{t}-1}+\mathrm{J}_{\mathrm{t}-1}\left(\mathrm{y}_{\mathrm{t} \mid \mathrm{T}}-\mathrm{y}_{\mathrm{t} \mid \mathrm{t}-1}\right) \text {, } \\
& P_{t-1 \mid T}=P_{t-1 \mid t-1}+J_{t-1}\left(P_{t \mid T}-P_{t \mid t-1}\right) J_{t-1}^{\prime} \text {, where } \\
& \mathrm{J}_{\mathrm{t}-1}=\mathrm{P}_{\mathrm{t}-|| t-1} \Gamma^{\prime}\left[\mathrm{P}_{\mathrm{t} \mid t-1}\right]^{-1} \text {. }
\end{aligned}
$$

It should be clear from the above that to implement the smoothing algorithm the quantities $\mathrm{y}_{\mathrm{t} \mid \mathrm{t}}$ and $\mathrm{P}_{\mathrm{t} \mid \mathrm{t}}$ generated during the filter pass must be stored.

With reference to the TVP model it is obvious that the parameters of interest are embedded in the matrices $\mathrm{A}_{\mathrm{t}}, \mathrm{Q}$, and $\mathrm{R}$. The description of the above filtering and the smoothing algorithms assumes that these parameters are known. In fact, we want to determine these parameters and this is achieved by maximizing the innovation form of the likelihood function. The one step ahead innovation and its covariance matrix are defined by the equations (5.8 and 
5.9) and since these are assumed to be independent and conditionally Gaussian, the log likelihood function (without the constant term) is given by,

$$
\log (\mathrm{L})=-\sum_{\mathrm{t}=1}^{\mathrm{T}} \log \left|\Sigma_{\mathrm{t}}(\Theta)\right|-\sum_{\mathrm{t}=1}^{\mathrm{T}} \nu_{\mathrm{t}}^{\prime}(\Theta) \Sigma_{\mathrm{t}}^{-1}(\Theta) \nu_{\mathrm{t}}(\Theta) .
$$

In this expression $\Theta$ is specifically used to emphasize the dependence of the $\log$ likelihood function on the parameters of the model. Once the function is maximized with respect to the parameters of the model, the next step of smoothing can start using those estimated parameters.

Maximization of the function in (5.13) may be achieved using one of two approaches. The first one depends on algorithm like Newton-Raphson and the second one is known as the EM (Expectation Maximization) algorithm. In this paper we employ Newton-Raphson technique to achieve our objective and since the likelihood function is reasonably well behaved, maximization is achieved quite quickly. In some modeling situations it may not be so straightforward. EM algorithm has been reported to be quite stable in the presence of bad starting values, although it may take longer to converge. Some researchers report that when good starting values are hard to obtain, a combination of the two approaches may be useful. In that situation it is preferable to employ EM algorithm first in order to obtain an intermediate estimates and then switch to Newton-Raphson method. Interested readers may refer to Shumway and Stoffer (2000, p. 323).

In an alternative set up, we explore the interaction of the momentum variables derived from the two asset markets. We label them as $\mathrm{mR}_{\mathrm{t}}$ for the equity market and the corresponding one from the housing market as $\mathrm{mH}_{\mathrm{t}}$.

In the second set up, the observation equation is:

$$
\begin{aligned}
\mathrm{FF}_{\mathrm{t}} & =\alpha_{0}+\alpha_{1, \mathrm{t}}\left(\pi_{\mathrm{t}}-0.02\right)+\alpha_{2, \mathrm{t}}\left(\mathrm{u}_{\mathrm{t}}-0.04\right)+\alpha_{3, \mathrm{t}} \mathrm{mR}_{\mathrm{t}-1}+\alpha_{4, \mathrm{t}} \mathrm{mH}_{\mathrm{t}-1}+\varepsilon_{\mathrm{t}} \\
\varepsilon_{\mathrm{t}} & \sim \mathrm{N}\left(0, \sigma_{\varepsilon}^{2}\right)
\end{aligned}
$$


The state transition equation will be same as above except that the interpretation of the two parameters $\alpha_{3, \mathrm{t}}$ and $\alpha_{4, \mathrm{t}}$ would be different.

\section{RESULTS}

Tables 1 and 2 present the results of the econometric estimation:

\begin{tabular}{llllll}
\hline \multicolumn{6}{c}{ Table 1 } \\
\multicolumn{5}{c}{$\begin{array}{l}\text { Parameter Estimates of the Time Varying Parameter Model Using Kalman Filter } \\
\text { Federal Funds Rate Model with Feedback from Equity and Housing Markets }\end{array}$} \\
\hline$\alpha_{0}$ & $\sigma_{\varepsilon}^{2}$ & $\sigma_{\eta 1}^{2}$ & $\sigma_{\eta 2}^{2}$ & $\sigma_{\eta 3}^{2}$ & $\sigma_{\eta 4}^{2}$ \\
$5.35628^{*}$ & $0.01879^{*}$ & $3.39 \mathrm{E}-05$ & $0.01620^{*}$ & $2.72 \mathrm{E}-21^{*}$ & $0.00028^{*}$ \\
$(0.10052)$ & $(0.00382)$ & $(4.86 \mathrm{E}-05)$ & $(0.00224)$ & $(2.30 \mathrm{E}-22)$ & $(7.13 \mathrm{E}-05)$ \\
\hline
\end{tabular}

Estimates reported here are obtained from maximising the innovation form of the likelihood function. Numerical optimisation procedure in GAUSS is used without any parameter restriction. The standard errors (reported below the parameters in parentheses) are obtained from the hessian matrix at the point of convergence. These estimates are robust to different starting values including different specification of the prior covariance matrix. Significance at $5 \%$ level is indicated by *.

\begin{tabular}{|c|c|c|c|c|}
\hline \multicolumn{5}{|c|}{$\begin{array}{l}\text { Residual Diagnostics and Model Adequacy Tests } \\
\text { Federal Funds Rate Model with Feedback from Equity and Housing Markets }\end{array}$} \\
\hline Portmanteau & ARCH & KS Test & MNR & Recursive T \\
\hline 0.418 & 0.270 & .079 & 0.999 & \\
\hline \multicolumn{5}{|c|}{$\begin{array}{l}\text { Entries are p-values for the respective statistics except for the KS statistic. These diagnostics are computed from } \\
\text { the recursive residual of the measurement equation, which corresponds to the real dividend process. The null } \\
\text { hypothesis in portmanteau test is that the residuals are serially uncorrelated. The ARCH test checks for no serial } \\
\text { correlations in the squared residual up to lag } 26 \text {. Both these test are applicable to recursive residuals as } \\
\text { explained in Wells (1996, page 27). MNR is the modified Von Neumann ratio test using recursive residual for } \\
\text { model adequacy (see Harvey (1990, chapter 5). Similarly, if the model is correctly specified then Recursive T } \\
\text { has a Student's t-distribution (see Harvey (1990, page 157). KS statistic represents the Kolmogorov-Smirnov } \\
\text { test statistic for normality. } 95 \% \text { and } 99 \% \text { significance levels in this test are } 0.121 \text { and } 0.145 \text { respectively. When } \\
\text { KS statistic is less than } 0.121 \text { or } 0.145 \text { the null hypothesis of normality cannot be rejected at the indicated level } \\
\text { of significance. }\end{array}$} \\
\hline
\end{tabular}


Figure 1

Federal Funds Rate Model with Feedback from Equity and Housing Markets Parameter $\alpha_{1}$ (Coefficient of inflation)

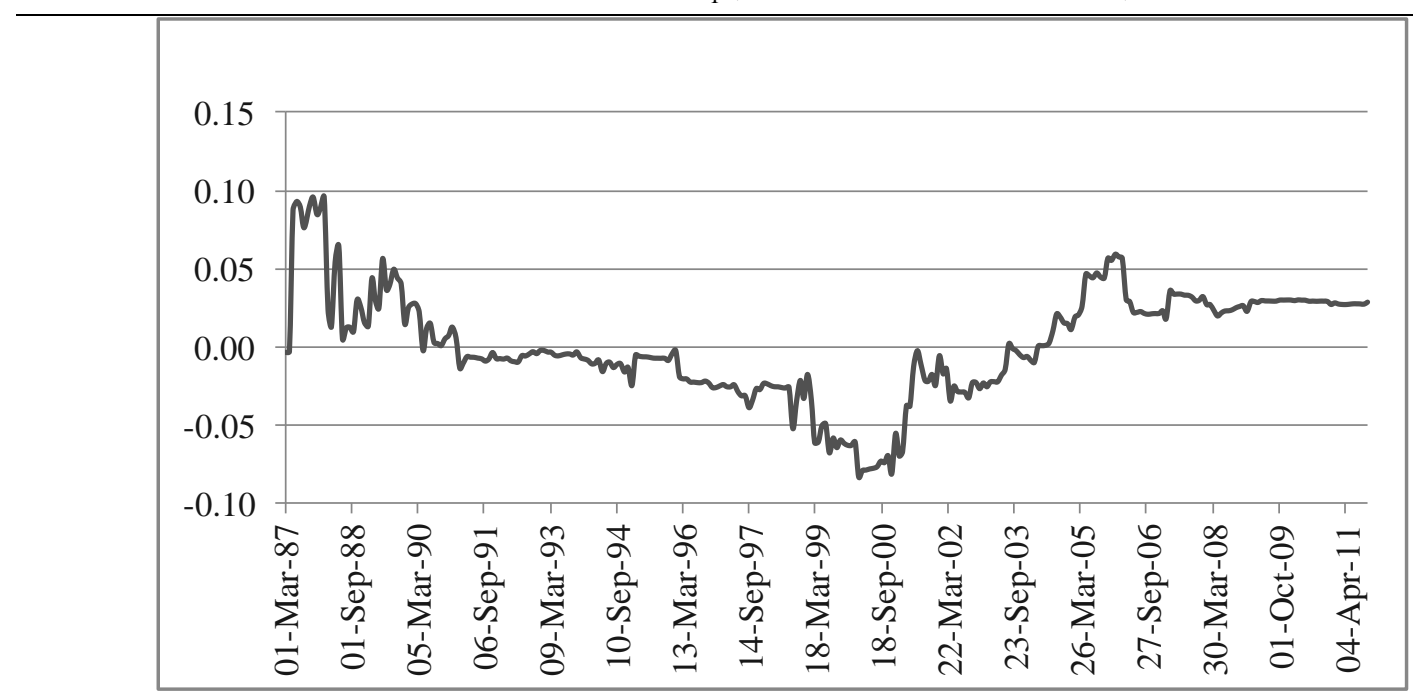

Figure 2

Federal Funds Rate Model with Feedback from Equity and Housing Markets

Parameter $\alpha_{2}$ (Coefficient of unemployment)

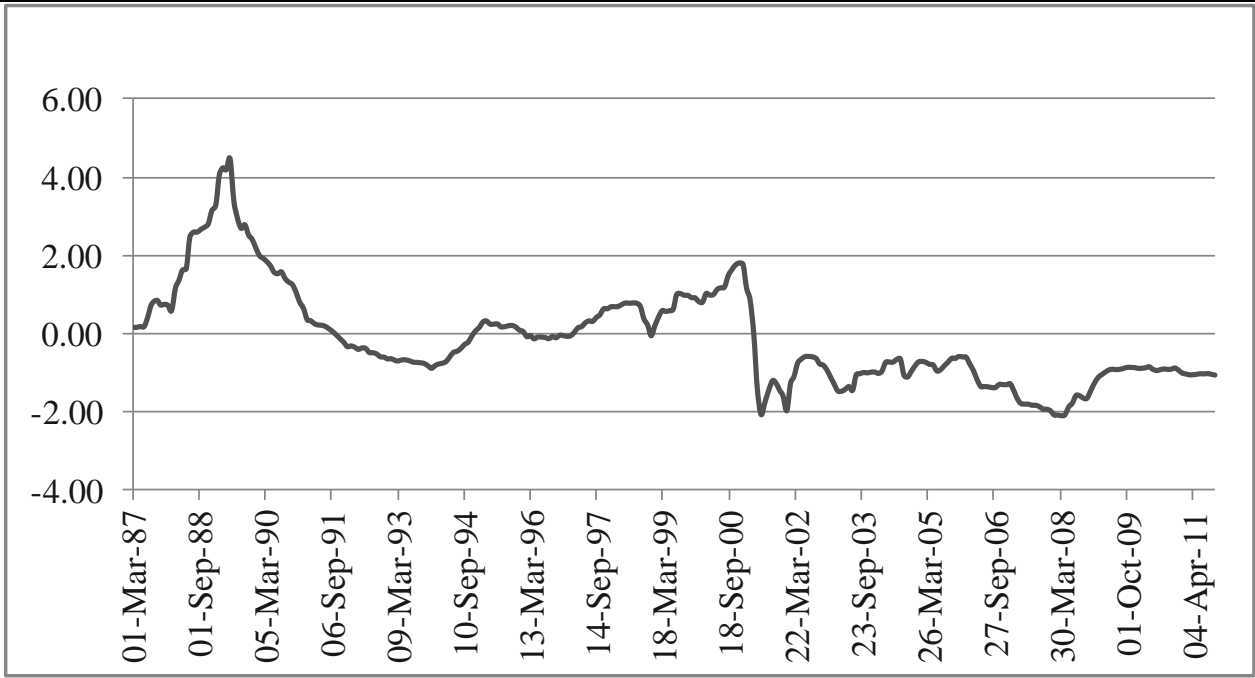


Figure 3

Federal Funds Rate Model with Feedback from Equity and Housing Markets

Parameter $\alpha_{3}$ (Coefficient of lagged equity market return)

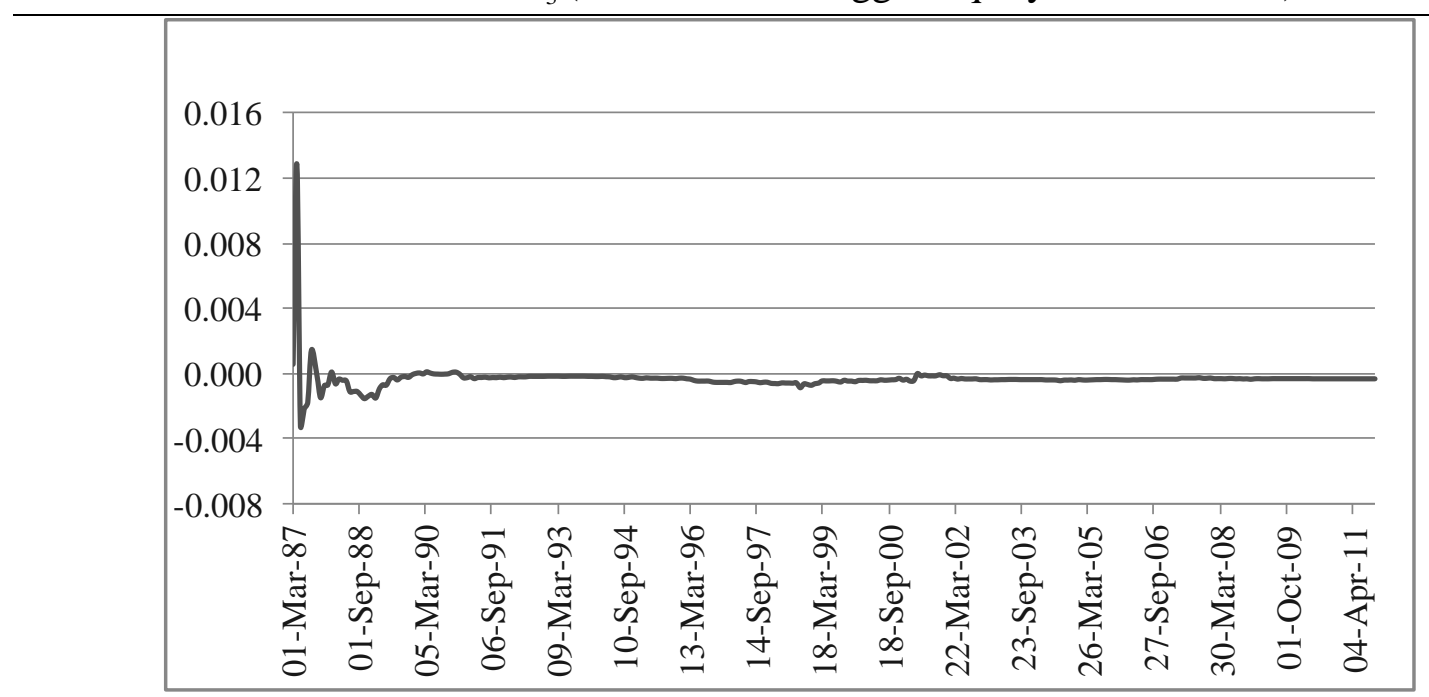

\section{Figure 4}

Federal Funds Rate Model with Feedback from Equity and Housing Markets Parameter $\alpha_{4}$ (Coefficient of lagged housing market return)

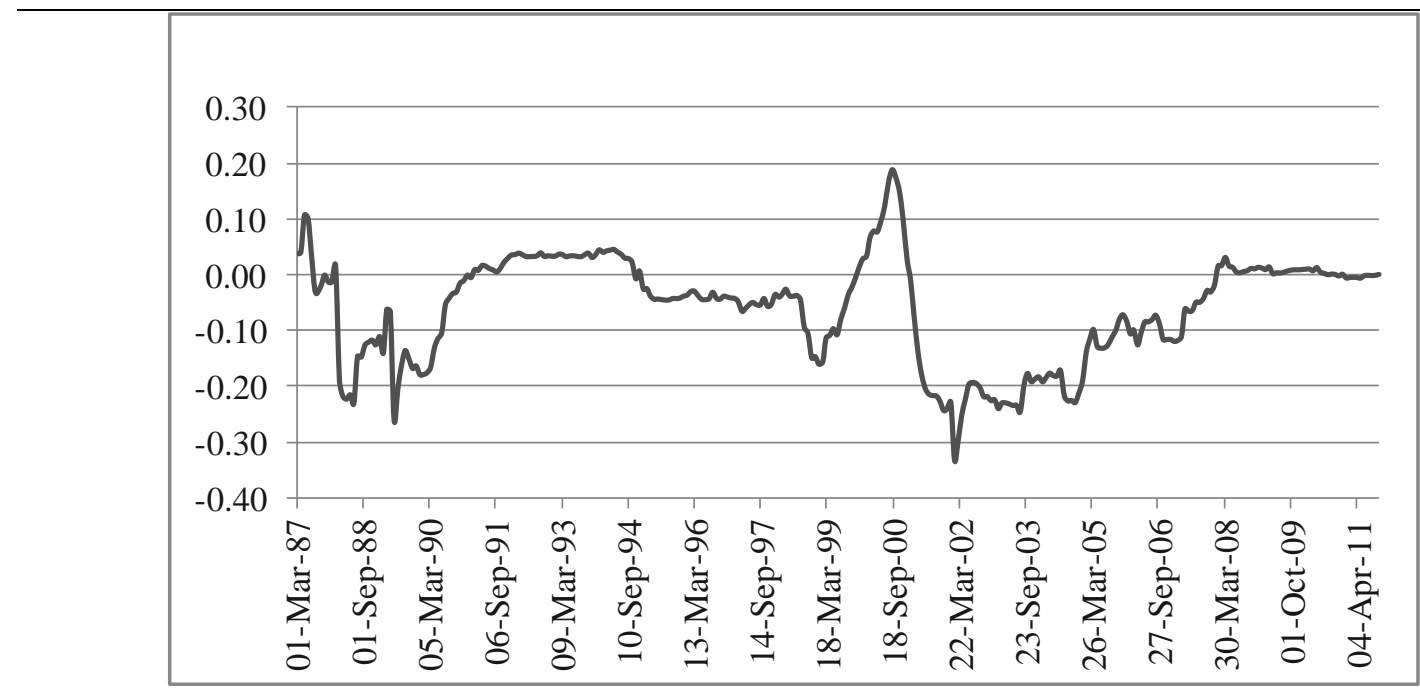

The results reported lead us to make five observations. First, with our modelling approach using Markov switching we obtain a reasonable parameter for the average Fed funds 
rate of about 5.35. This is the sum of both the real interest rate of about 2-3\% on average and the average rate of inflation of about $2-2.5 \%$ excluding volatile food and energy prices. Next we consider the remaining four terms of equation 5.14. We discuss each term separately. The deviation from the average inflation second term yields a varying coefficient illustrated in Figure 1.

The second observation that we derive from this table is that the inflation coefficient is very volatile ranging from .10 to -.10 unlike the coefficients reported in standard Taylor Rules models such as Kahn (2010). We view our results with their variability as more informative because these estimates are dynamic instead of being static for the entire sampling period. During the 1987 to 1991 when the economy slowed down the inflation coefficient decreases since the Fed funds rate were declining; from 1992 to 1997 inflation plays no important role so its coefficient is close to zero; from 1999 to 2002 with the bursting of the internet bubble, and the recession that followed Fed funds dropped significantly so the inflation coefficient correctly takes a negative value. Recall that Taylor argues that the Fed kept an easy policy for much longer than needed to 2004 and this is described by the low values of the inflation coefficient during this period; finally, the inflation coefficient increases during 2005 to 2008 and remain stable and low during the 2008-2011 period.

Third, the coefficient of unemployment in Figure 2 has a similar volatile pattern with estimated values ranging from 4.0 to -2.0 Similar argument can be made to those just reported in the previous paragraph. These two graphs generalize the constant Taylor rule coefficients and allow for a much richer interpretation of Fed policies.

Fourth, the coefficient $\alpha_{3}$ in Figure 3 is telling us that the lagged equity market return did not have any influence on the setting of FFt. In other words the equity market was decoupled from the process. This result confirms that both the Greenspan and later the Bernanke Fed never attempted to use Fed Funds to lean against the equity bubble. As is reported in Evanoff, Kaufman and Malliaris (2012), the Jackson Hole consensus favoured an asymmetric approach to bubbles.

Fifth, however, the coefficient of the lagged real estate returns, $\alpha_{4}$ in Table 4 shows some interesting episodes. Initially, around 1988-90 we have the real estate crisis associated with the savings and loans bankruptcies when the Fed lowered the Fed Funds rate to contain the crisis and the recession that took place. Between 1991 to early 1999 it was close to zero implying that 
this sector of the market was decoupled from the FFt settings. From March 1999 to March 2002 the housing coefficient increases to .10 and then drops to -.30. This can be interpreted that momentum in housing both as prices were going up in 1999 and when their momentum declined during the 2002 recession was a strategic variable in the Fed's deliberations; we also know ex post that from 2002 to 2007 lower Fed Funds rate fuelled the housing momentum. As we indicated earlier there is an alternative explanation for the housing momentum during this period that Bernanke calls the global savings glut hypothesis. In our equation 5.14 we cannot test for this hypothesis however. We conclude that the real estate momentum coefficient in Figure 4 offers fresh new insights about the behaviour of Fed Funds.

\section{CONCLUDING REMARKS}

Taylor Rules have been the topic of extensive theoretical, econometric and policy research. They are useful policy tools to guide monetary policy, particularly during times that such policy is driven by the Fed's dual mandate. The Fed's policies become more difficult during periods of financial instabilities and crises and in such times simple rules may not adequate. In this paper we consider two new independent variables as inputs to the Taylor Rule. These are the equity and housing momentum variables and are introduced to investigate the potential usefulness of these two variables in guiding the Fed to lean against potential bubbles. Such effectiveness cannot adequately be evaluated if the Taylor Rule estimation follows the standard regression methodology that has been criticized in the literature to be econometrically incorrect. Using a time varying parameter estimation methodology we find that equity momentum as an input in the Taylor Rule does not contribute to changes in Fed Funds. However, the housing momentum plays an important role econometrically and can be a useful tool in setting Fed Funds rates. 


\section{References:}

Bernanke, B., 2010, Monetary Policy and the Housing Market, at the Annual Meeting of the American Economic Association, Atlanta, Georgia, January 3.

Bernanke, B., 2013, The Federal Reserve and the Financial Crisis, Princeton: Princeton University Press.

Bhar, R. and Malliaris, A., 2011, Dividends, Momentum and Macroeconomic Variables as Determinants of the U.S. Equity Premium Across Economic Regimes, Review of Behavioral Finance, 3, 27-53.

Cochrane, J., 2011, Determinacy and Identification with Taylor Rules, Journal of Political Economy, 119, 565-615.

Evanoff, D., Kaufman, G. and Malliaris, A. G., 2012, editors, New Perspectives on Asset Price Bubbles: Theory, Evidence and Policy, New York: Oxford University Press.

Kaminsky, G. L. and Reinhart. C. M., 1999, The Twin Crises: The Causes of Banking and Balance of Payments Problems, American Economic Review, 89, 473-500.

Kim, C-J, Kishor, N. K., and Nelson, C. R., 2006, A Time-Varying Parameter Model for a Forward-Looking Monetary Policy Rule based on Real-Time Data, Working paper (UWEC 32 2007), Department of Economics, University of Washington.

Kohn, D. L., 2006. Monetary Policy and Asset Prices, Speech given at Monetary Policy: A Journey from Theory to Practice, a European Central Bank Colloquium held in honor of Otmar Issing. Frankfurt, Germany.

Kohn, D., 2007, John Taylor Rules, at the Conference on John Taylor's Contributions to Monetary Theory and policy, Federal Reserve Bank of Dallas, Dallas, Texas, October 12.

Kohn, D. L., 2008, Monetary Policy and Asset Prices Revisited, Cato Journal, 29, 31-44.

Koijen, R. S. J., Rodriguez, J. C. and Sbuelz, A., 2009, Momentum Return and Mean-Reversion in Strategic Asset Allocation, Management Science, 55, 1199-1233.

Mandler, M., 2008, Decomposing Federal Funds Rate forecast uncertainty using real-time data, University of Giessen, MPRA Paper No. 18768, posted 20, November 2009/14:25, online at http://mpra.ub.uni-muenchen.de/18768/.

Mehra, Y. P. and Sawhney, B., 2010, Inflation measure, Taylor Rules, and the GreenspanBernanke years, Economic Quarterly, 96 (2), 123-151. 
Österholm, P., 2005, The Taylor Rule: A Spurious Regression? Bulletin of Economic Research, 57 (3), 217-247.

Shumway, R. H. and Stoffer, D. S., 2000, Time Series Analysis and Its Applications, New York: Springer.

Taylor, J. B., 1993, Discretion versus policy rules in practice, Carnegie-Rochester Conference Series on Public Policy, 39, 195-214.

Taylor, J. B., 2007, Housing and Monetary Policy, National Bureau of Economic Research, Inc., Working Paper \#13682. 